\title{
Optimal DG Unit Placement and Sizing in Radial Distribution Network for Power Loss Minimization and Voltage Stability Enhancement
}

\author{
Benalia M'hamdi^, Madjid Teguar², Benaissa Tahar³ \\ ${ }_{1}^{1}$ Applied Automation and Industrial Diagnostics Laboratory, Faculty of Science and Technology, University of Djelfa, P. O. B. 3117, \\ Djelfa, Algeria \\ 2 Electrical Research Laboratory (L.R.E), National Polytechnic School, 10 Rue des Frères OUDEK, El Harrach 16200, Algiers, Algeria \\ ${ }^{3}$ Department of Electrical Engineering, Faculty of Science and Technology, University of Djelfa, P. O. B. 3117, Djelfa, Algeria \\ * Corresponding author, e-mail: mhbenalia@yahoo.fr
}

Received: 02 October 2019, Accepted: 15 November 2019, Published online: 22 January 2020

\begin{abstract}
The optimal allocation and size of decentralized generating units are essential to minimize power losses, while meeting the demand for active and reactive power in a distribution system. In other words, most of the total energy produced can be efficiently exploited by end users. In addition, if the DGs are of optimal size and location in the distribution system, the reliability, stability and efficiency of the power system are guaranteed. This paper focuses on reducing power losses and improving the voltage profile by accurately identifying the optimal location and sizing of Distributed Generation based on three indexes, namely the IVM Index Vector Method, the VDI Voltage Deviation Index and the VSI Voltage Stability Index. Two types of DGs were considered for the analysis: DGs operating with unit power factor and DGs operating with a lagging power factor. Three optimization algorithms are applied to determine the optimal sizes of decentralized generation units in a power distribution network which are GWO, WOA and PSO. The results obtained in this article show that the three algorithms give very similar values. DG at lagging power factor gives better results compared with those obtained with DGs at unity power factor. In terms of loss reduction and minimum bus voltage, the best results are obtained for the VSI index with a DG at a power factor of 0.9 .
\end{abstract}

Keywords

Distributed Generation (DG), radial distribution system, voltage stability, power loss reduction

\section{Introduction}

Distribution networks are an important part of a power supply system since the supply of electricity to consumers is ensured by an efficient distribution system. In general, the radial distribution network has a high $\mathrm{R} / \mathrm{X}$ ratio, which leads to more power losses and voltage drop. A large amount of total power losses in the power grid occurs in the distribution network accounting for about $13 \%$ of the total network generation [1]. The minimization of power losses plays a crucial role in economic exploitation and the reduction of energy costs. In recent years, the use of Distributed Generation units in distributed radial networks has attracted the attention of many industrialists and researchers because of their effectiveness in reducing power losses and improving voltage stability. Generally, the DG term refers to the small scale electric power generators. Noting that, the renewable energy-based DG has been growing rapidly worldwide in recent years due to its promising potential to reduce the share of fossil energy consumption in electricity production and to mitigate harmful carbon emissions [2, 3].

In general, the DG units can be classified in three types based on their ability to inject and absorb real and reactive powers: type I operates at unity power factor and injects active power (PV cells), type II injects reactive power (capacitors) and type III injects real power and injects or consumes reactive power(synchronous generators).

Based on the review of literature, deferent approaches based on classical, and meta-heuristics algorithms have been recently proposed for the optimal placement and sizing of DG units in a distribution system for power loss minimization and voltage stability enhancement. 
In $[4,5]$, an analytical approach was proposed for DG Sizing and Sitting in radial distribution networks to reduce power losses.

This work has attempted to investigate the performance of the distribution system in the presence of two types of DG sources, DG at unity power factor and lagging power factor $\mathrm{DG}$, to reduce power losses and voltage profile enhancement. For identification of the optimum location of DG the authors have used the Index Vector Method (IVM), Voltage Stability Index (VSI) and Voltage Deviation Index (VDI).

In this investigation, three optimization algorithms are applied to determine the optimal sizes of decentralized production units in a power distribution network namely the Grey Wolf Optimization Algorithm (GWO) [6], the Whale Optimization Algorithm (WOA) [7] and the Particle Swarm Optimization (PSO) [8]. The proposed method are tested on standard IEEE 33-bus and IEEE 69-bus test systems by considering loss minimization and voltage profile improvement.

\section{Problem formulation}

In this study, the optimal sizing and sitting of DG units in radial distribution networks is formulated as a multi-objective problem by considering as objectives the minimization of active power losses and improving the voltage profile and enhancing the voltage stability.

The mathematical construction of the Objective Function is given as:

$\mathrm{OF}=\operatorname{Min}\left(f_{1} ; f_{2}\right)$,

where $f_{1}$ and $f_{2}$ are the total system power loss and the bus voltage deviation respectively.

Firstly, the optimal location of DG is determined from the following concepts:

- Case (i) Index Vector Method

- Case (ii) Voltage Stability Index

- Case (iii) Voltage Deviation Index.

Secondly, the optimal location DG size is determined using the optimization algorithms.

\subsection{The active power losses}

Among the most important objectives of the implementation of sources in radial distribution networks is the reduction of total power losses. In radial distribution networks, each receiving bus is fed by solely one sending bus.
Well, the line active power losses between the receiving and sending end buses can be determinate as follows [1]:

$P_{L}(i)=r_{i}\left|I_{i}\right|^{2}=r_{i} \frac{\left(P_{i}^{2}+Q_{i}^{2}\right)}{V_{i}^{2}}$.

Therefore, the total system power loss (the first objective function) can be calculated as following [1]:

$\sum_{i=2}^{N_{\text {bus }}} P_{L}(i)=\sum_{i=2}^{N_{\text {bus }}} r_{i}\left|I_{i}\right|^{2}=\sum_{i=2}^{N_{\text {bus }}} r_{i} \frac{\left(P_{i}^{2}+Q_{i}^{2}\right)}{V_{i}^{2}}$,

where $r_{i}$ is the line resistance connected between the sending end node $i-1$ and the receiving end node $i$; $I$ current of branch $i ; V_{i}$ voltage of node $i ; P_{i}$ and $Q_{i}$ active and reactive power load fed through node $i$.

So, the Total System Loss Reduction (TLR) can be calculated using the flowing Eq. (3):

TLR $\%=\frac{\sum_{i=1}^{N_{b u s}} P_{L w o u t \mathrm{DG}}-\sum_{i=1}^{N_{b u s}} P_{L w \mathrm{DG}}}{\sum_{i=1}^{N_{\text {bus }}} P_{L w o u t \mathrm{DG}}} \times 100 \%$,

where $P_{L w \mathrm{DG}}$ and $P_{L w o u t \mathrm{DG}}$ are the total line losses in the system with the employment of DG and without employment DG respectively.

\subsection{Index Vector Method}

Among the indices used to determine the optimal location of Distributed Generation, is the Index Vector Method (IVM) [9]. The IVM for bus $i$ is given by:

$\operatorname{IVM}(i)=\frac{1}{V_{i}^{2}}+\frac{I_{q}(k)}{I_{p}(k)}+\frac{Q_{e f f}(i)}{Q_{T}}$.

$I_{p}(k), I_{q}(k)$ are the real and imaginary parts of the current in the $k^{\text {th }}$ branch. $Q_{\text {eff }}(i)$ and $V(i)$ are the reactive load, the voltage at the $i^{\text {th }}$ bus. $Q_{T}$ is the total reactive load.

To find the optimal locations for DG unit placement using IVM, firstly, store the buses with index arranged in decreasing order in a vector according to their positions. Secondly, select the buses with normalized voltage magnitudes less than 1.01. The bus with the highest Index and with normalized voltage magnitudes less than 1.01 are the best suitable locations for DG placement [9].

Normalized voltage magnitudes $V_{n o r m}(i)$ for the $i^{\text {th }}$ bus can be calculated by the following formula:

$V_{\text {norm }}(i)=V_{\text {norm }}(i) / 0.95$,

where $V(i)$ is the base case voltage magnitude of the $i^{\text {th }}$ bus. 


\subsection{Voltage Stability Index}

For proper operation and to prevent the system from the block out conditions, the stability must be maintained. Voltage stability is therefore one of the most important security indices. To find the most sensitive bus to voltage collapse in the system, Murty and Kumar in 2015 [3] proposed Voltage Stability Index (VSI) which can be defined at each node as follows:

$$
\operatorname{VSI}_{i+1}=\frac{4 X_{i}}{V_{i}^{2}}\left(\frac{P_{i+1}^{2}}{Q_{i+1}}+Q_{i+1}\right)
$$

where $\mathrm{VSI}_{i}$ is the stability index for node $i(2,3, \ldots, \mathrm{N}$ bus $)$, $P_{i}$ and $Q_{i}$ are total active and reactive power load fed through at $i$ bus, $V_{i}$ is voltage of the $i^{\text {th }}$ node, $X_{i}$ is reactance of the $i^{\text {th }}$ branch.

In order to attain the stable operation of the radial distribution system, the Voltage Stability Index (VSI) value should be less than unity. To avoid the possibility of voltage collapse, the VSI of all buses should become closer to zero. Buses with the highest VSI values are more sensitive and are candidates for DG placement [3].

\subsection{Voltage Deviation Index}

Maintaining bus voltage within acceptable limits is one of the most important criteria. The introduction of DGs into an existing radial network improves nodes voltage because DGs provide locally a portion of energy to the load and thus reduce losses in the feeders; therefore, the voltage deviation is improved.

The Voltage Deviation Index (VDI) for bus $i$ can be formulated as given in the following $[10,11]$ :

$$
\mathrm{VDI}_{i}=\sum_{i}^{\mathrm{NB}}\left|1-V_{i}\right| \text {, }
$$

where $V_{i}$ is the Voltage at the $i^{\text {th }}$ bus in (pu) and NB is the Number of Buses.

\subsubsection{Constraints}

- Equality Constraints: The equality constraints represent power balance equations. The power balance equation in transmission system in presence of Distributed Generation units can be expressed as follows:

$$
\left\{\begin{array}{l}
\sum_{i=1}^{N G} P_{\mathrm{G} i}+\sum_{i=1}^{N D} P_{\mathrm{DG} i}=P_{\mathrm{D}}+P_{L} \\
\sum_{i=1}^{N G} Q_{\mathrm{G} i}=Q_{\mathrm{D}}+Q_{L}
\end{array} .\right.
$$

- Inequality Constraints:

- Voltage constraint: The voltage magnitude must keep within the specified limits at each bus:

$$
V_{\min } \leq V_{i} \leq V_{\max },
$$

where $V_{\min }$ and $V_{\max }$ are respectively the lower and upper limits of the $i^{\text {th }}$ bus voltage.

- Distributed Generation size constraint: The power generated by each DG unit must be less than the total active load of the system.

$$
\left\{\begin{array}{l}
P_{\mathrm{DG} i}^{\min } \leq P_{\mathrm{DG} i} \leq P_{\mathrm{DG} i}^{\max } \\
Q_{\mathrm{DG} i}^{\min } \leq Q_{\mathrm{DG} i} \leq Q_{\mathrm{DG} i}^{\max }
\end{array}\right.
$$

where $P_{\mathrm{DG} i}$ and $Q_{\mathrm{DG} i}$ are the $\mathrm{DG}$ active and reactive power components injected at the $i^{\text {th }}$ bus.

\section{Test systems description}

In this study, the proposed algorithms are used to determine the optimal location and size of the DG unit and have been carried out on two different IEEE test networks namely the 33-bus [10-14] and the 69-bus [10, 14] radial distribution networks.

The IEEE 33-bus radial distribution network is shown in Fig. 1. It consists of thirty-three buses and thirty-two branches (lines), the total system load is $3.715 \mathrm{MW}$ and $2.3 \mathrm{MVAr}$, its voltage level is $12.66 \mathrm{kV}[12,13]$. The second one (Fig. 2) is 69-bus radial distribution network contains sixty nine buses, sixty eight lines with a total load of 3.80 MW and 2.69 MVAr [14]. The operating constrains in RDS with the algorithms parameters are listed in Table 1.

The IEEE 33 and 69-bus systems are examined as test cases with two types of DG units the first one operates at unity power factor, injects only real power and

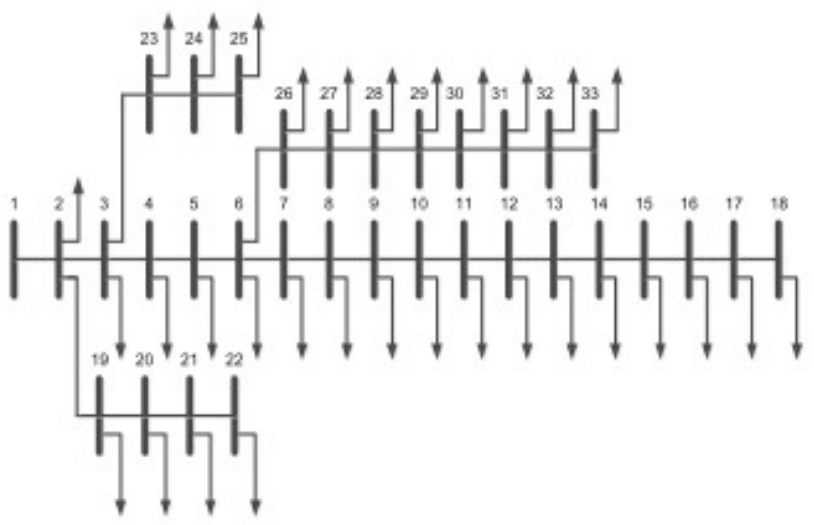

Fig. 1 Single-line diagram of IEEE 33-bus distribution system 


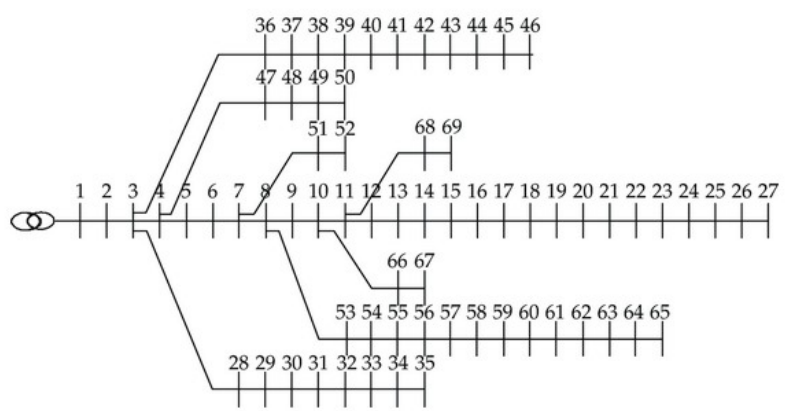

Fig. 2 Single-line diagram of IEEE 69-bus distribution system

Table 1 The used parameters

\begin{tabular}{lccc}
\hline Algorithm & GWO & WOA & PSO \\
\hline Maximum iteration & 500 & 500 & 500 \\
Search agents No. & 30 & 30 & 30 \\
DG sizing limits & & $0 \leq P_{\text {DGi }} \leq 5 \mathrm{MW}$ & \\
Voltage limits & & $0.9 \leq V_{i} \leq 1.05$ & \\
\hline
\end{tabular}

the second one operates at lagging power factor $(0.9 \mathrm{pf}$ lag) injects both active and reactive powers.

\subsection{Results and discussion}

\subsubsection{Results using Index Vector Method}

According to the Index Vector Method profile and the normalized voltage curves (Figs. 3 to 6), it is found that for the 33-bus system, buses 26 to 30 exhibits the highest vector method index and their normalized voltages are less than 1.01. Thus, these buses can be chosen as appropriate locations for DG units. In the present investigation, the node 30 is chosen as the optimal location of the DG unit installation (IVM has the maximum value). Similarly, for bus system 69, at node 61, the Index Vector Method reaches a maximum value of 2.412 and a normalized voltage of $0.919 \mathrm{pu}$ which is less than 1.01 (Figs. 5 and 6). Thus, the node 61 is chosen as the optimal location of the DG.

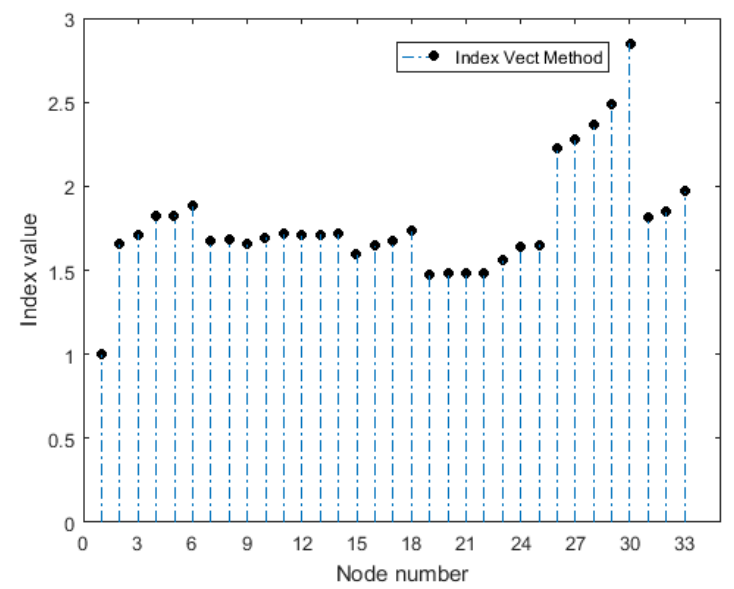

Fig. 3 33-bus system vector method index

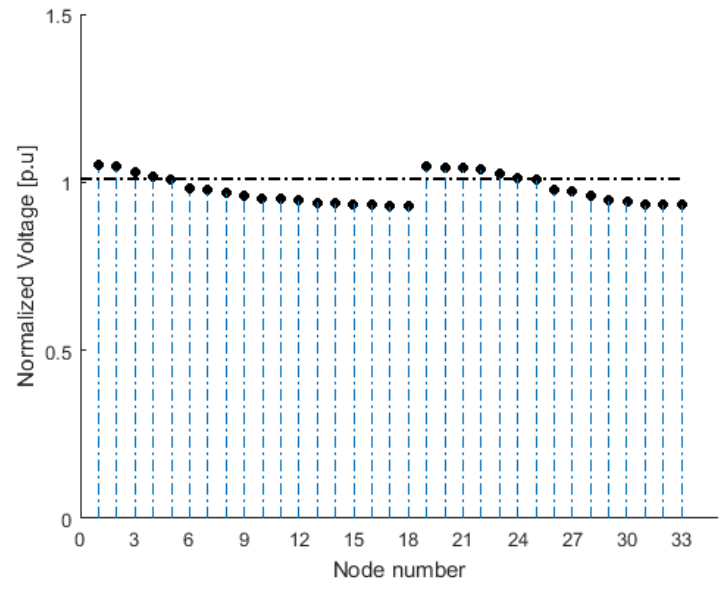

Fig. 4 33-bus system normalized voltage

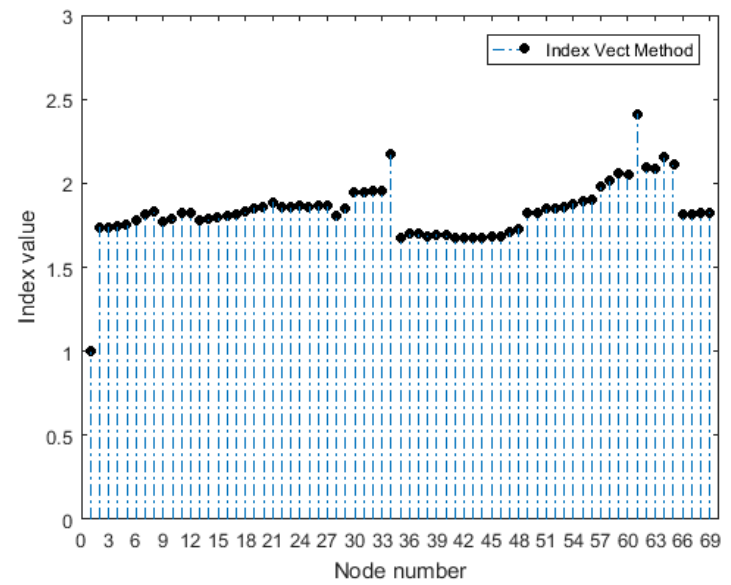

Fig. 5 69-bus system vector method index

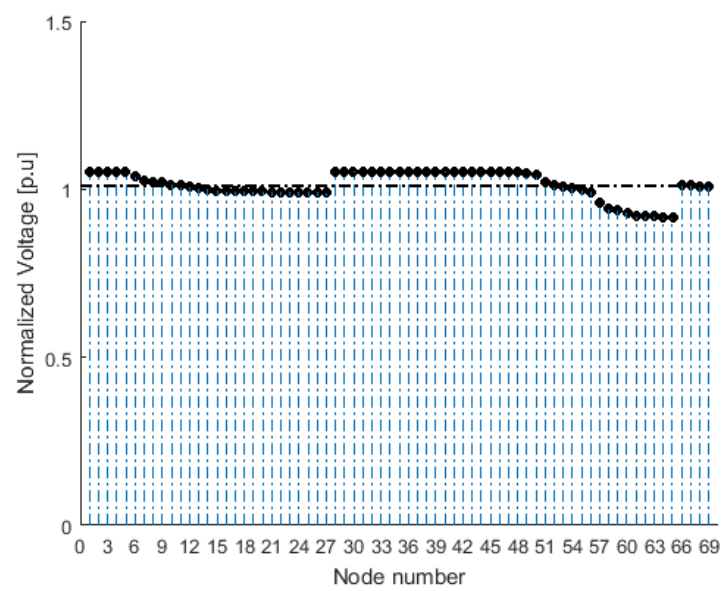

Fig. 6 69-bus system normalized voltage

\subsubsection{Results for 33-bus test system using Index Vector Method}

The presented investigation has been carried out on 33-bus radial distribution test system with a total active and reactive power demand of $3715 \mathrm{~kW}$ and $2300 \mathrm{kVAr}$. Without installation of DG units, the real and the reactive power losses are respectively $281.5877 \mathrm{~kW}$ and $187.9595 \mathrm{kVAR}$. Minimum 
voltage before installation of DG unit is $0.882 \mathrm{pu}$ at bus 18 as given in Table 2 and shown in Fig. 7. After placement at node 30 of the DG at unity power factor, the total power losses decrease, and reach the values of $151.6819 \mathrm{~kW}$ for active power and 106.913 kVAr for reactive power, which shows reductions of $46.13 \%$ and $43.12 \%$ respectively. After the installation of the DG, bus 18 is still at the minimum voltage of $0.918 \mathrm{pu}$. With DG at 0.9 lag power factor, the active and reactive power losses became $106.3945 \mathrm{~kW}$ and $77.0343 \mathrm{kVAr}$, which reveal reductions of $62.21 \%$ and $59.02 \%$ respectively. As shown in Table 2, it is observed from the results that the losses are lower with DG operating at $0.9 \mathrm{pf}$ when compared to DG operating at unity pf. This is due to the fact that the locally produced reactive power decreases the reactive power called from the substation. Noted that the optimal DG size obtained at lagging

\begin{tabular}{|c|c|c|c|c|c|}
\hline Methods & $\begin{array}{c}\text { DG } \\
\text { location }\end{array}$ & $\begin{array}{l}\text { DG optimal } \\
\text { size }(\mathrm{MW})\end{array}$ & $\begin{array}{c}P_{\text {loss }} \\
(\mathrm{kW}) \\
(\mathrm{TLR} \%)\end{array}$ & $\begin{array}{c}Q_{\text {loss }} \\
(\mathrm{kVAr}) \\
(\mathrm{TLR} \%)\end{array}$ & $\begin{array}{l}V_{\min } \\
(\mathrm{pu})\end{array}$ \\
\hline $\begin{array}{l}\text { Base } \\
\text { case }\end{array}$ & - & - & 281.578 & 187.560 & 0.882 \\
\hline \multirow{2}{*}{ GWO } & upf & 1.6319 & $\begin{array}{c}151.6819 \\
(46.13)\end{array}$ & $\begin{array}{c}106.913 \\
(43.12)\end{array}$ & 0.918 \\
\hline & lag & 1.7995 & $\begin{array}{c}106.3945 \\
(62.21)\end{array}$ & $\begin{array}{l}77.0343 \\
(59.015)\end{array}$ & 0.928 \\
\hline \multirow{2}{*}{ WOA } & upf & 1.6321 & $\begin{array}{c}151.6909 \\
(46.13)\end{array}$ & $\begin{array}{c}106.9616 \\
(43.09)\end{array}$ & 0.9186 \\
\hline & lag & 1.7995 & $\begin{array}{c}106.3664 \\
(62.226)\end{array}$ & $\begin{array}{l}77.1702 \\
(58.94)\end{array}$ & 0.928 \\
\hline \multirow{2}{*}{ PSO } & \multirow{2}{*}{30} & 1.6320 & $\begin{array}{l}151.682 \\
(46.13)\end{array}$ & $\begin{array}{c}106.8708 \\
(43.14)\end{array}$ & 0.9183 \\
\hline & & 1.7995 & $\begin{array}{c}106.3662 \\
(62.23)\end{array}$ & $\begin{array}{l}77.1704 \\
(58.94)\end{array}$ & 0.928 \\
\hline
\end{tabular}

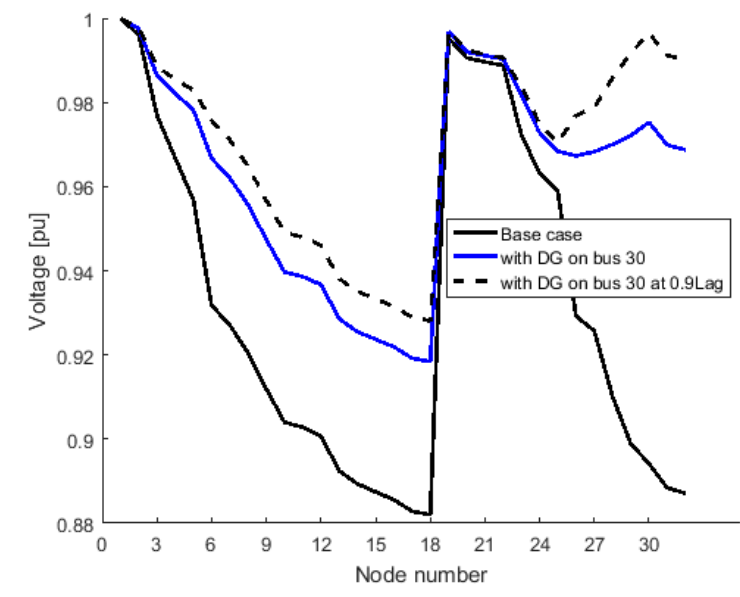

Fig. 7 Voltage profiles of the 33-bus system power factor $1.7995 \mathrm{MW}$ is higher compared to the optimal size obtained at unity power factor 1.6319 MW. As shown in Fig. 7, the voltage profile is also improved with DG at lagging power factor. The minimum voltage obtained at bus 18 is 0.928 pu which is better compared to the voltage obtained with DG at unity power factor. It is therefore essential to note the impact of reactive power available in DG on losses reduction and voltage improvement. The results obtained for DG unit operating at unity power factor, are also given in Table 2 using three optimizer algorithms method (GWO, WOA and PSO).

Active and reactive power losses variation in each branch of the 33-bus system are shown in Figs. 8 and 9 for the two cases with no DG connected and with DG at unity and lagging power factor connected to the selected bus. For the IEEE 33-bus test system, the branches 2 and 5 have the highest losses, particularly in case without and with DG at unit power factor.

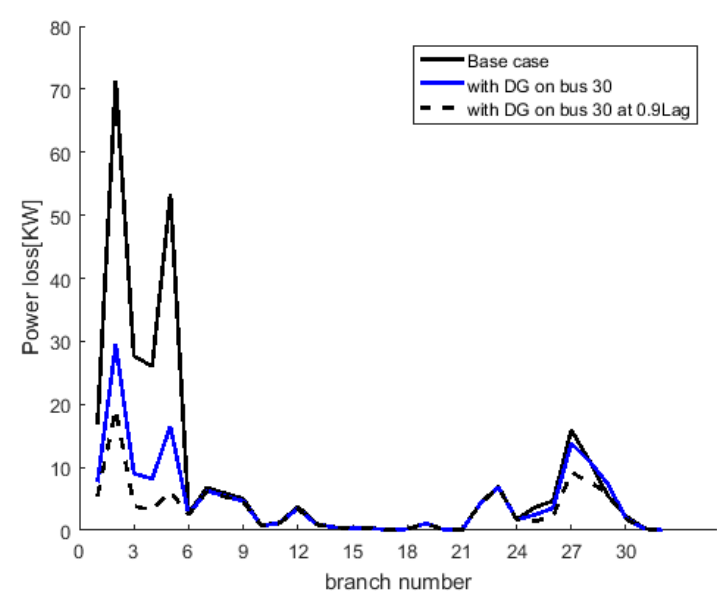

Fig. 8 Active power line loss of the 33-bus system

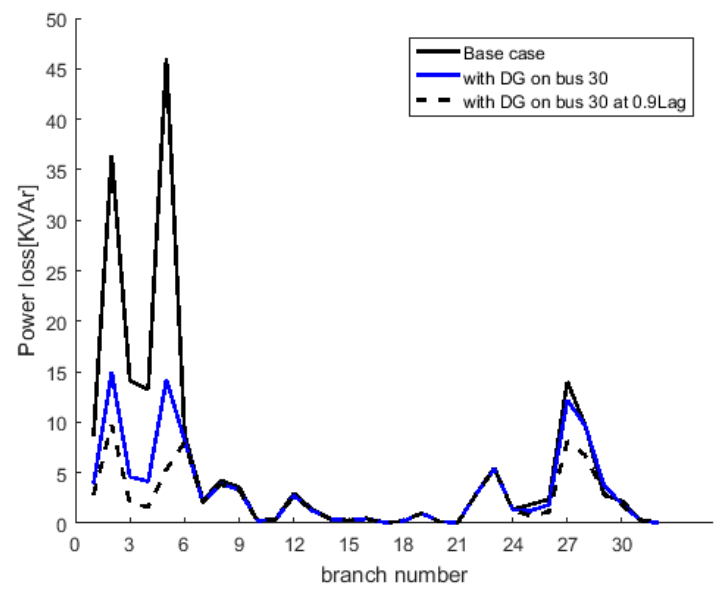

Fig. 9 Reactive power line loss of the 33-bus system 


\subsubsection{Results for 69-bus test system using Index Vector Method}

The results have been obtained for 69-bus test system for two types of DG units the first one operates at unity power factor and the second one operates at $0.9 \mathrm{pf}$ lag and with a total active and reactive power demand of $3792 \mathrm{~kW}$ and 2694.1 kVAr. Without DG the real and the reactive power losses are $337.2778 \mathrm{~kW}$ and $150.6536 \mathrm{kVAr}$ respectively and the voltage is at its minimum value of $0.869 \mathrm{pu}$ at bus 65 as given in Table 3 and shown in Fig. 10. With the DG installation at bus 61 , the active and the reactive power losses obtained are respectively $113.0785 \mathrm{~kW}$ and $54.3294 \mathrm{kVAr}$ in case of DG operating at pf unit which presents reductions of $66.47 \%$ and $63.93 \%$ respectively compared to the case without DG installation and in case with DG operating at $0.9 \mathrm{pf}$ lag, the active and the reactive

\begin{tabular}{|c|c|c|c|c|c|}
\hline Methods & $\begin{array}{c}\text { DG } \\
\text { location }\end{array}$ & $\begin{array}{l}\text { DG optimal } \\
\text { size }(\mathrm{MW})\end{array}$ & $\begin{array}{c}P_{\text {loss }} \\
(\mathrm{kW}) \\
(\mathrm{TLR} \%)\end{array}$ & $\begin{array}{c}Q_{\text {loss }} \\
(\mathrm{kVAr}) \\
(\mathrm{TLR} \%)\end{array}$ & $\begin{array}{l}V_{\min } \\
(\mathrm{pu})\end{array}$ \\
\hline $\begin{array}{l}\text { Base } \\
\text { case }\end{array}$ & & & 281.578 & 187.560 & 0.882 \\
\hline \multirow{2}{*}{ GWO } & upf & 1.9043 & $\begin{array}{c}113.0785 \\
(66.47)\end{array}$ & $\begin{array}{c}54.3294 \\
(63.93)\end{array}$ & 0.9594 \\
\hline & lag & 2.0446 & $\begin{array}{l}51.7467 \\
(84.65)\end{array}$ & $\begin{array}{c}28.0549 \\
(81.37)\end{array}$ & 0.9627 \\
\hline \multirow{2}{*}{ WOA } & upf & 1.9043 & $\begin{array}{c}113.0868 \\
(66.47)\end{array}$ & $\begin{array}{c}54.2342 \\
(64.00)\end{array}$ & 0.9598 \\
\hline & lag & 2.0446 & $\begin{array}{l}51.7502 \\
(84.66)\end{array}$ & $\begin{array}{c}28.0638 \\
(81.37)\end{array}$ & 0.9629 \\
\hline \multirow{2}{*}{ PSO } & \multirow{2}{*}{61} & 1.9043 & $\begin{array}{l}113.062 \\
(66.478)\end{array}$ & $\begin{array}{l}54.2726 \\
(63.975)\end{array}$ & 0.9596 \\
\hline & & 2.0446 & $\begin{array}{l}51.7485 \\
(84.657)\end{array}$ & $\begin{array}{c}28.0791 \\
(81.36)\end{array}$ & 0.9628 \\
\hline
\end{tabular}

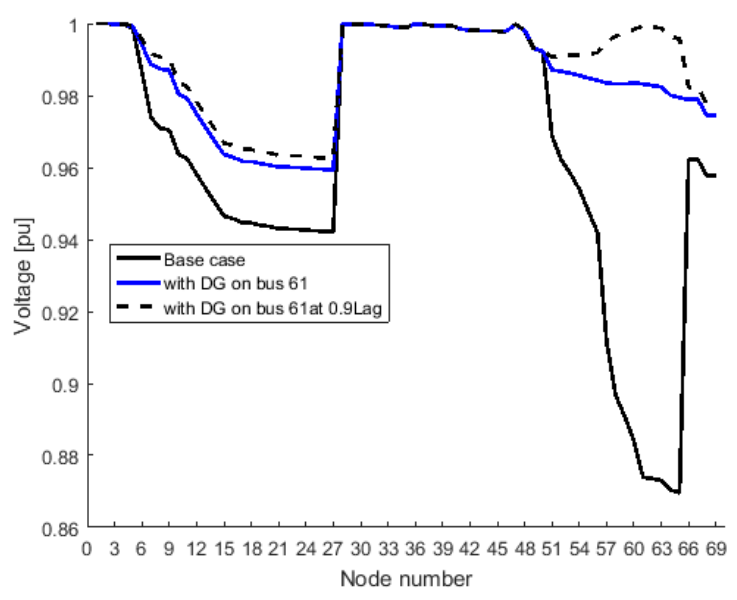

Fig. 10 Voltage profiles for 69-bus system power losses obtained are $51.7467 \mathrm{~kW}$ and 28.0549 $\mathrm{kVAr}$ which presents reductions of $84.65 \%$ and $81.37 \%$ respectively compared to the case without DG installation. Noted that the losses are lower with DG operating at $0.9 \mathrm{pf}$ when compared to DG operating at unity pf, this is due to the decrease in reactive power called from the substation and provided by the DG unit. As in the case of IEEE 33-bus system, the optimal DG size obtained for the 69-bus system at lagging power factor $2.0446 \mathrm{MW}$ is higher compared to the optimal size obtained at unity power factor $1.9043 \mathrm{MW}$. As shown in Fig. 10, the profile of the voltage also improves with the installation of DG, in particular with that with a lagging power factor, the voltage is at its minimum value at bus 27 equal to 0.9594 pu for the DG with unit pf and equal to $0.9627 \mathrm{pu}$ for the lag pf DG, as shown in Table 3.

Figs. 11 and 12 show the active and reactive power losses in each of the branches of the 69-bus system for the two cases where a DG is connected to the selected bus,

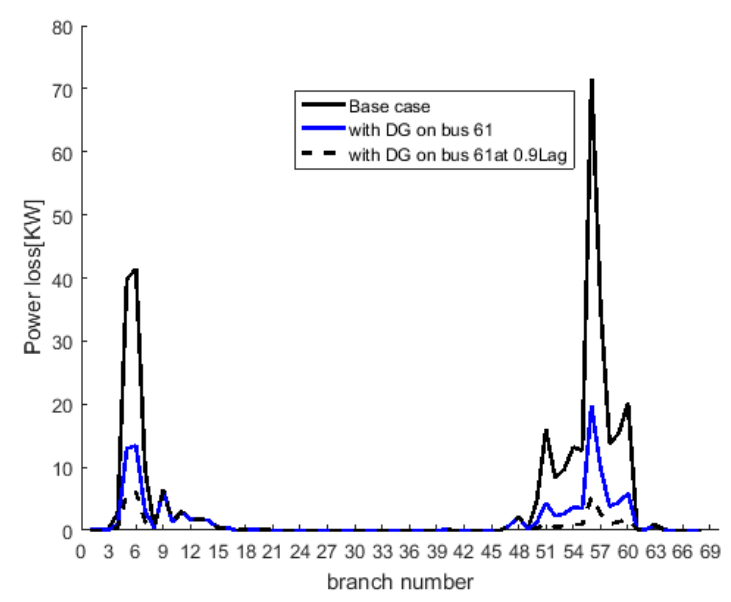

Fig. 11 Active power lines loss of the 69-bus system

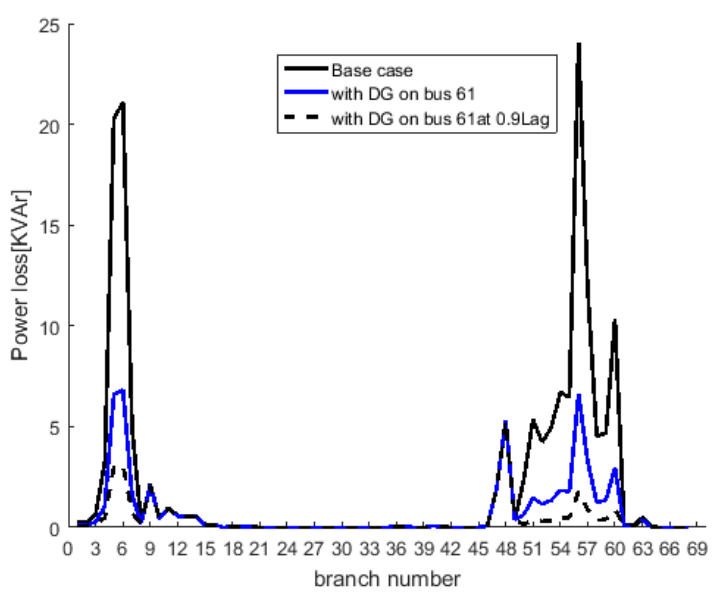

Fig. 12 Reactive power lines loss of the 69-bus system 
in the case of a unit power factor and in the case of a lagging power factor and when no DG is connected. It is observed from the figures that, for the IEEE 69-bus test system, the branches 6 and 58 have the highest losses.

\subsection{Results using Voltage Stability Index}

The buses are sorted in descending order according to the Voltage Stability Index. For the 33-bus system, bus 6 has the highest Voltage Stability Index (the most sensitive bus to voltage collapse) of the network, so this bus is selected for the DG location; In addition, buses 18 and 33 are also selected for the simulation since they have the lowest voltage values. Similarly for the 69-bus system, the node 61 exhibits the highest Voltage Stability Index in the network. Thus, the node 61 is chosen as the optimal location of the DG. In addition bus 27 and 8 are also selected for the simulation, as bus 27 is the furthest away bus of the network, and bus 8 for its strategic node in the network. The Voltage Stability Index profiles are determined for both network test systems with and without DGs placement and are shown in Figs. 13 to 17.

All simulation results using the Voltage Stability Index and various algorithms for the two test systems are presented in Tables 4 and 5.

\subsubsection{Results for 33-bus test system using Voltage Stability Index}

In the 33-bus system, without allocating DG, the $6^{\text {th }}$ bus has the maximum VSI value and is equal to 0.0111 . The minimum voltage of the system is $0.882 \mathrm{pu}$ at $18^{\text {th }}$ bus (bus 33 is the furthest away bus in the second longest branch of the network and has low voltage value of $0.8867 \mathrm{pu}$ ).

The Voltage Stability Index profiles, when the optimal DG unit size at up has been connected at buses 6,18 and 33, respectively and also when the optimal DG unit

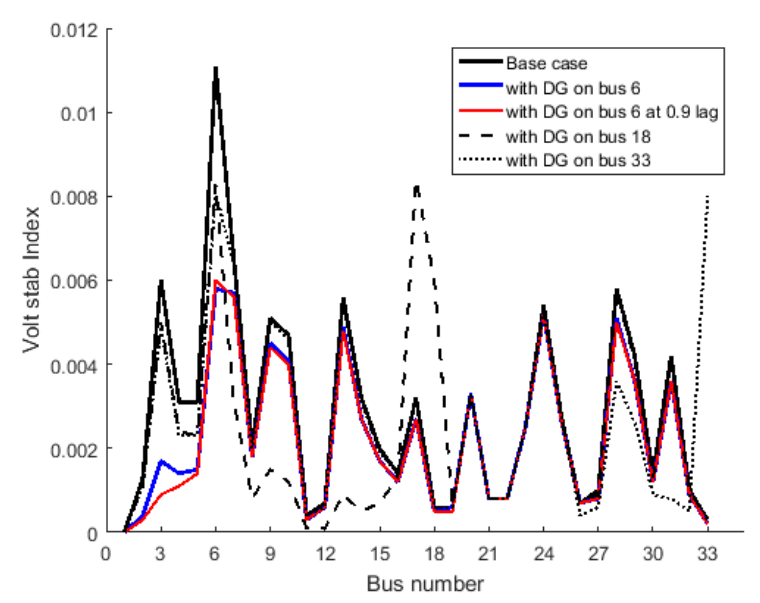

Fig. 13 The 33-bus system Voltage Stability Index

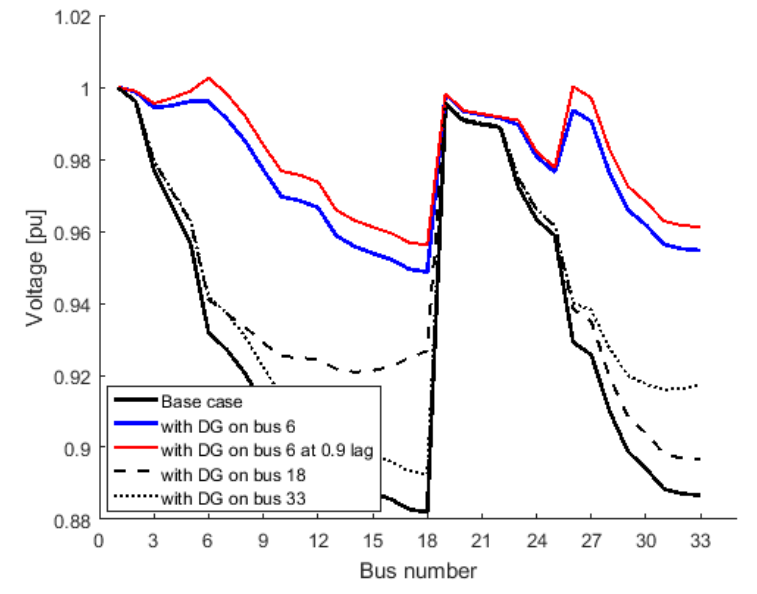

Fig. 14 Voltage profiles of 33-bus system

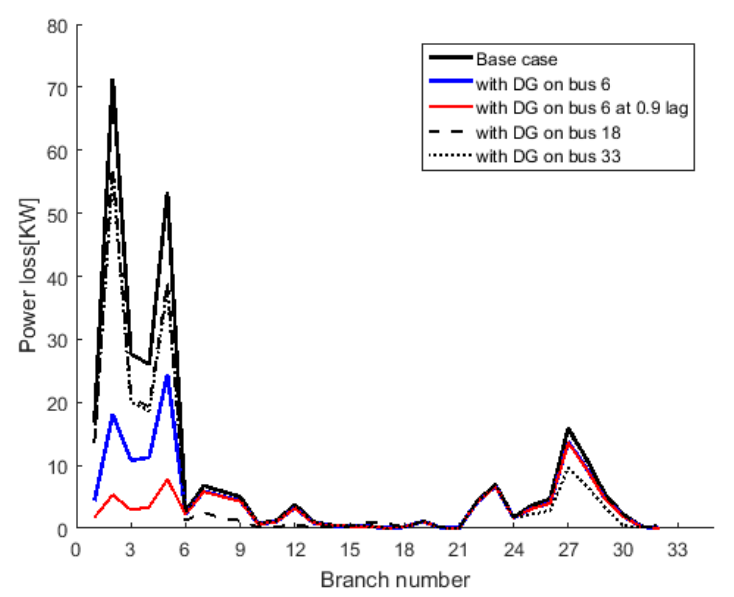

Fig. 15 Active power lines loss of the 33-bus system

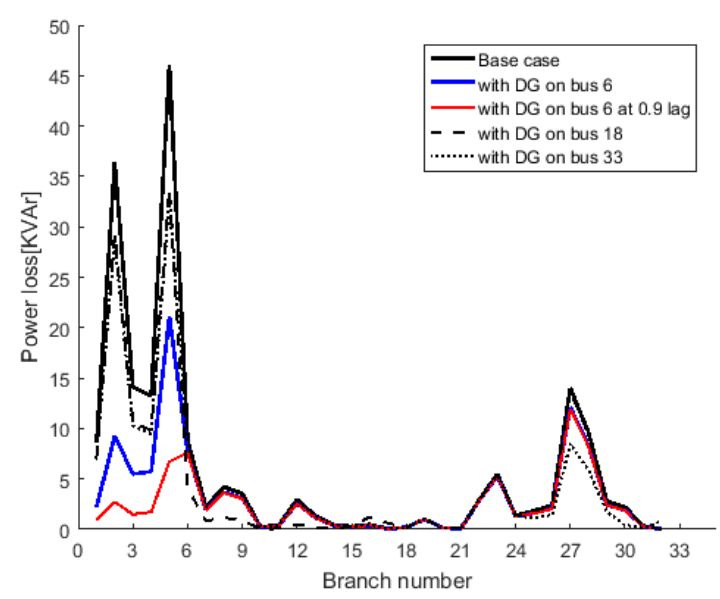

Fig. 16 Reactive power lines loss of the 33-bus system

size at $0.9 \mathrm{pf}$ has been connected at bus 6 , are presented in Fig. 13, while Fig. 14 presents the voltage profiles of network buses for the same cases.

In the case where the decentralized production units at unit power factor are connected to buses 6,18 and 33, the optimal sizes are respectively 3.2405 MW, $0.4163 \mathrm{MW}$ and $0.452 \mathrm{MW}$. The total active power losses 


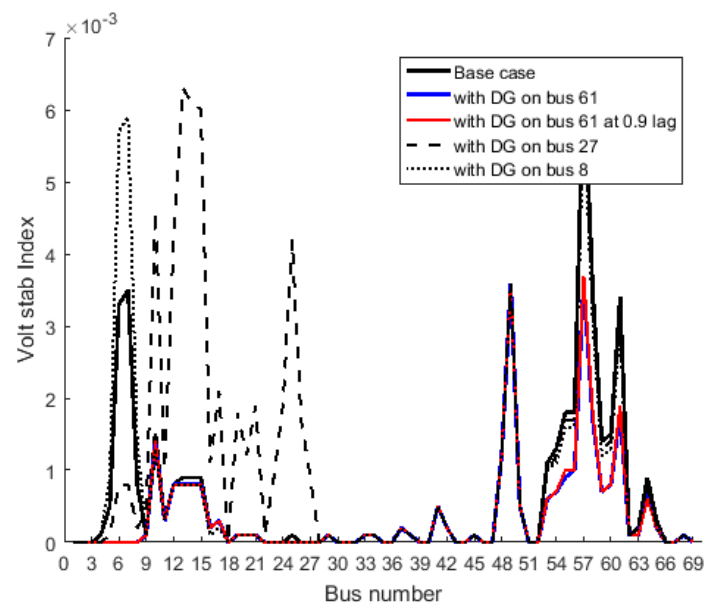

Fig. 17 The 69-bus system Voltage Stability Index

Table 4 Simulation results of 33-bus system

\begin{tabular}{|c|c|c|c|c|c|}
\hline Methods & $\begin{array}{c}\text { DG } \\
\text { location }\end{array}$ & $\begin{array}{l}\text { DG optimal } \\
\text { size }(\mathrm{MW})\end{array}$ & $\begin{array}{c}P_{\text {loss }} \\
(\mathrm{kW}) \\
(\mathrm{TLR} \%)\end{array}$ & $\begin{array}{c}Q_{\text {loss }} \\
(\mathrm{kVAr}) \\
(\mathrm{TLR} \%)\end{array}$ & $\begin{array}{l}V_{\min } \\
(\mathrm{pu})\end{array}$ \\
\hline $\begin{array}{l}\text { Base } \\
\text { case }\end{array}$ & & & 281.578 & 187.560 & 0.882 \\
\hline \multirow{2}{*}{ GWO } & upf & 3.2405 & $\begin{array}{l}145.15 \\
(48.45)\end{array}$ & $\begin{array}{c}105.206 \\
(44.03)\end{array}$ & 0.9487 \\
\hline & lag & 3.0206 & $\begin{array}{c}96.48 \\
(65.736)\end{array}$ & $\begin{array}{c}74.2516 \\
(60.496)\end{array}$ & 0.9562 \\
\hline \multirow{2}{*}{ WOA } & upf & 3.2406 & $\begin{array}{c}144.0732 \\
(48.835)\end{array}$ & $\begin{array}{c}104.4284 \\
(44.44)\end{array}$ & 0.9476 \\
\hline & lag & 3.0206 & $\begin{array}{c}96.2806 \\
(65.81)\end{array}$ & $\begin{array}{l}74.0696 \\
(60.59)\end{array}$ & 0.9555 \\
\hline \multirow{2}{*}{ PSO } & \multirow{2}{*}{6} & 3.2406 & $\begin{array}{l}145.5037 \\
(48.327)\end{array}$ & $\begin{array}{c}105.4582 \\
(43.89)\end{array}$ & 0.949 \\
\hline & & 3.0206 & $\begin{array}{c}96.2816 \\
(65.81)\end{array}$ & $\begin{array}{c}74.0704 \\
(60.59)\end{array}$ & 0.9555 \\
\hline
\end{tabular}

Table 5 Simulation results of 69-bus system

\begin{tabular}{|c|c|c|c|c|c|}
\hline Methods & $\begin{array}{c}\text { DG } \\
\text { location }\end{array}$ & $\begin{array}{c}\text { DG optimal } \\
\text { size }(\mathrm{MW})\end{array}$ & $\begin{array}{c}P_{\text {loss }} \\
(\mathrm{kW}) \\
(\mathrm{TLR} \%)\end{array}$ & $\begin{array}{c}Q_{\text {loss }} \\
(\mathrm{kVAr}) \\
(\mathrm{TLR} \%)\end{array}$ & $\begin{array}{l}V_{\min } \\
(\mathrm{pu})\end{array}$ \\
\hline $\begin{array}{l}\text { Base } \\
\text { case }\end{array}$ & & & 337.3014 & 150.664 & 0.8697 \\
\hline \multirow{2}{*}{ GWO } & upf & 2.6874 & $\begin{array}{l}139.766 \\
(58.56)\end{array}$ & $\begin{array}{l}63.613 \\
(57.78)\end{array}$ & 0.9657 \\
\hline & lag & 2.6995 & $\begin{array}{c}73.5082 \\
(78.20)\end{array}$ & $\begin{array}{l}35.4285 \\
(76.48)\end{array}$ & 0.9685 \\
\hline \multirow{2}{*}{ WOA } & upf & 2.6878 & $\begin{array}{c}138.8929 \\
(58.82)\end{array}$ & $\begin{array}{l}63.2816 \\
(57.998)\end{array}$ & 0.9656 \\
\hline & lag & 2.6998 & $\begin{array}{l}72.7282 \\
(78.44)\end{array}$ & $\begin{array}{l}35.1375 \\
(76.68)\end{array}$ & 0.9683 \\
\hline \multirow{2}{*}{ PSO } & \multirow{2}{*}{61} & 2.6878 & $\begin{array}{c}140.8083 \\
(58.25)\end{array}$ & $\begin{array}{c}64.0093 \\
(57.51)\end{array}$ & 0.9658 \\
\hline & & 2.6998 & $\begin{array}{c}65.7631 \\
(80.503)\end{array}$ & $\begin{array}{c}32.5653 \\
(78.38)\end{array}$ & 0.9673 \\
\hline
\end{tabular}

after installation of the DGs are $145.151 \mathrm{~kW}, 217.498 \mathrm{~kW}$ and $214.763 \mathrm{~kW}$, representing reductions of $48.45 \%$, $22.76 \%$ and $23.73 \%$ respectively. The total reactive power losses are 105.206 kVAr, $144.349 \mathrm{kVAr}$ and $143.877 \mathrm{kVAr}$ wich represent reductions of $44.03 \%, 23.20 \%$ and $23.45 \%$ respectively. The maximum VSI of this system is improved from 0.0111 to 0.0058 and also the minimum voltage is improved to $0.9487 \mathrm{pu}$ after DG placed at bus 6 .

The simulation results indicate that the size of the DG obtained is lower for the lagging power factor $3.0206 \mathrm{MW}$ than for the unit power factor $3.2405 \mathrm{MW}$; similarly, the losses are lower for the DG at the lagging power factor than for the DG at the unit power factor. The total losses after placement at the 6th bus of DG at 0.9 power factor lag are $96.483 \mathrm{~kW}$ and $74.2516 \mathrm{KVAr}$ respectively witch present a reductions of $33.53 \%$ and $29.42 \%$ compared with those obtained with DG at unit power factor and a total reductions of $65.74 \%$ and $60.50 \%$ compared with losses obtained without DG.

Figs. 15 and 16 show the active and reactive power losses in each of the branches of the 33-bus system for the two cases where no DG is connected and in the case where a DG at unity and lagging power factor is connected to the selected bus. For the IEEE 33-bus test system, the branches 2 and 5 have the highest losses in case of DG at unit power factor while in case of lagging power factor the highest losses are at branch 27.

It is observed from Fig. 14, that the profile voltage also improves with a DG at the lagging power factor than with a DG at the unit power factor. The minimum bus voltage increases from $0.882 \mathrm{pu}$ without DG to $0.9562 \mathrm{pu}$ with a DG at $0.9 \mathrm{pf}$ lagging against $0.9487 \mathrm{pu}$ with a DG at the unit pf.

It should be noted that adding a DG unit to bus 18 or bus 33 brings a slight improvement in the profile of the bus voltage and also a slight decrease in power losses, as shown in Figs. 14, 15 and 16.

\subsubsection{Results for 69-bus test system using Voltage Stability Index}

Similarly, in the 69-bus test system without allocating DG, the maximum VSI value is at bus 61 and is equal to 0.0066 . The minimum voltage of the system is $0.8697 \mathrm{pu}$ at $65^{\text {th }}$ bus.

Fig. 17 shows the Voltage Stability Index profiles, when the optimal DG has been connected at buses 8, 27 and 61 respectively, while Fig. 18 presents the voltage profiles of network buses for the same cases. 


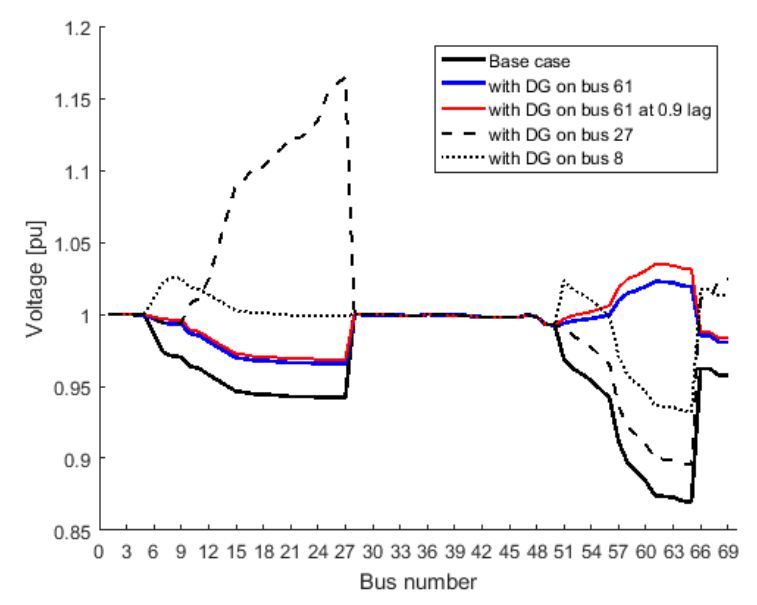

Fig. 18 Voltage profiles of 69-bus system

In the case where the decentralized production units at unit power factor are connected to buses 8,27 and 61 the optimal sizes are respectively $7.3582 \mathrm{MW}, 3.2956 \mathrm{MW}$ and 2.6874 MW. The total active power losses after installation of the DGs are $382.592 \mathrm{~kW}, 673.881 \mathrm{~kW}$ and $139.766 \mathrm{~kW}$, representing an increase of $13.42 \%$ and $99.78 \%$ when the DGs are connected to buses 8 and 27 , whereas a reduction of $58.56 \%$ is observed when the DG is connected to bus 61 . The total reactive power losses are 178.833 kVAr, 247.465 kVAr and 63.613 kVAr, wich represent an increase of $18.69 \%$ and $64.25 \%$ when the DGs are connected to buses 8 and 27, while a reduction of $57.78 \%$ is observed when the DG is connected to bus 61 .

After DG placement at bus 61, the maximum VSI of this system is improved from 0.007 to 0.0036 and also the minimum voltage is improved from $0.8697 \mathrm{pu}$ to $0.9657 \mathrm{pu}$.

The size of the DG obtained is higher for the lagging power factor 2.6995 MW; however, the power losses are lower. The total losses after placement at the $61^{\text {th }}$ bus of DG at 0.9 power factor lag are $73.5082 \mathrm{~kW}$ and $35.4285 \mathrm{KVAr}$ respectively witch present a reductions of $47.40 \%$ and $44.30 \%$ compared with those obtained with DG at unit power factor and a total reductions of $78.20 \%$ and $76.48 \%$ compared with losses obtained without DG.

The active and reactive power losses in each of the branches of the 69-bus system for the two cases where no DG is connected and in the case where a DG at unity and lagging power factor is connected to the selected bus are presented in Figs. 19 and 20. The highest power losses are in the branches 6 and 56.

It should be noted that the voltage improves more with a DG at the lagging power factor than with a DG at the unit power factor. The minimum voltage value increases from

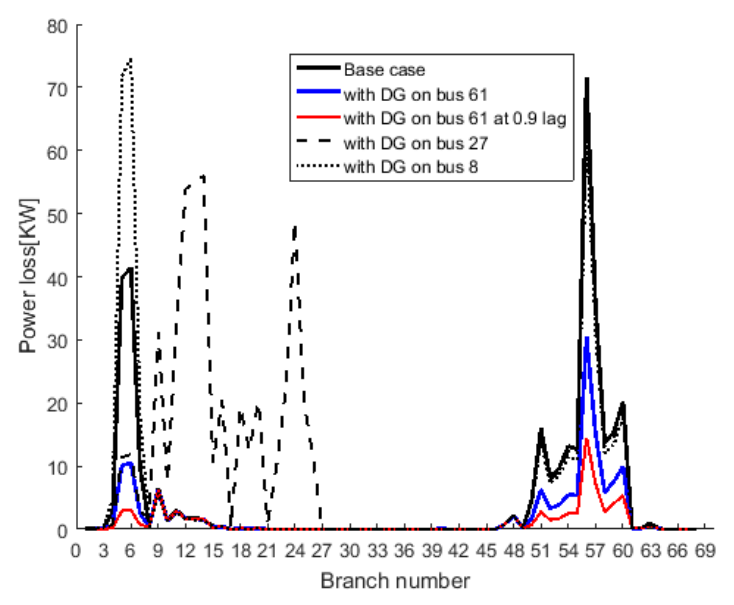

Fig. 19 Active power lines loss of the 69-bus system

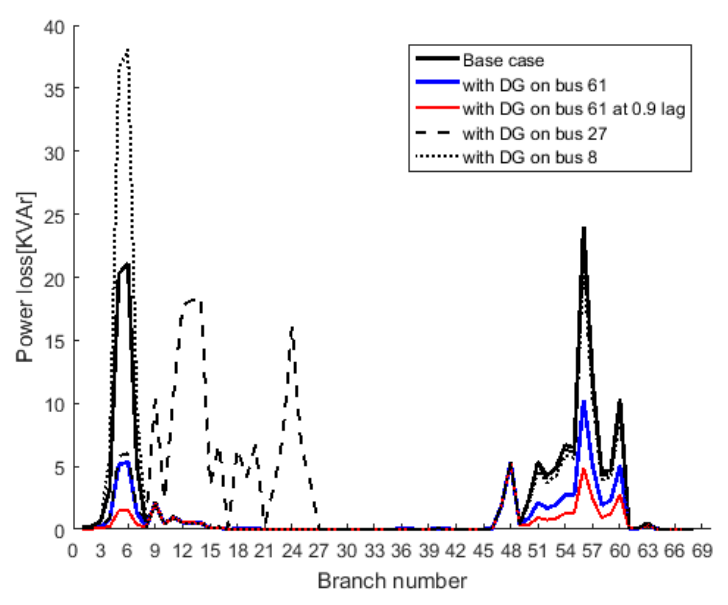

Fig. 20 Reactive power lines loss of the 69-bus system

0.8697 pu without DG to 0.9685 pu with a DG at 0.9 pf lagging against $0.9657 \mathrm{pu}$ with a DG at the unit pf.

It is worth note that adding a DG unit to bus 8 or bus 27 brings a slight improvement in the profile of the bus voltage, however, brings an increase in the power losses especially when the DG unit is connected to bus 27 as shown in Figs. 18, 19 and 20.

\subsection{Results using Voltage Deviation Index}

The buses are sorted in descending order according to the Voltage Deviation Index (the voltage deviation from the nominal voltage). For the 33-bus system, the buses selected for the DG site are bus 18 as the optimal location since it has the highest Voltage Deviation Index in the network (lowest voltage value) Figs. 21 and 22, bus 33 which has the highest Voltage Deviation Index in the second longest branch of the network and bus 6 for its strategic node in the network. Similarly for the 69-bus system, the node 65 exhibit the highest Voltage Deviation Index in the 


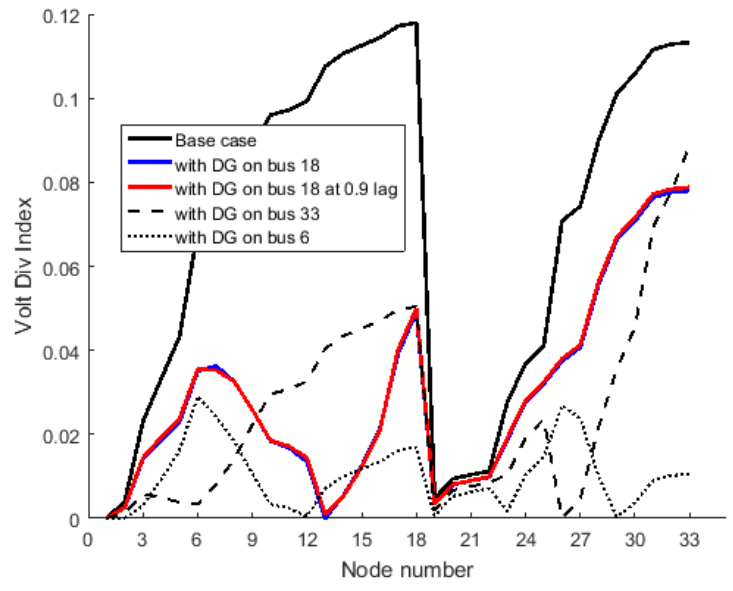

Fig. 21 The 33-bus system Voltage Deviation Index

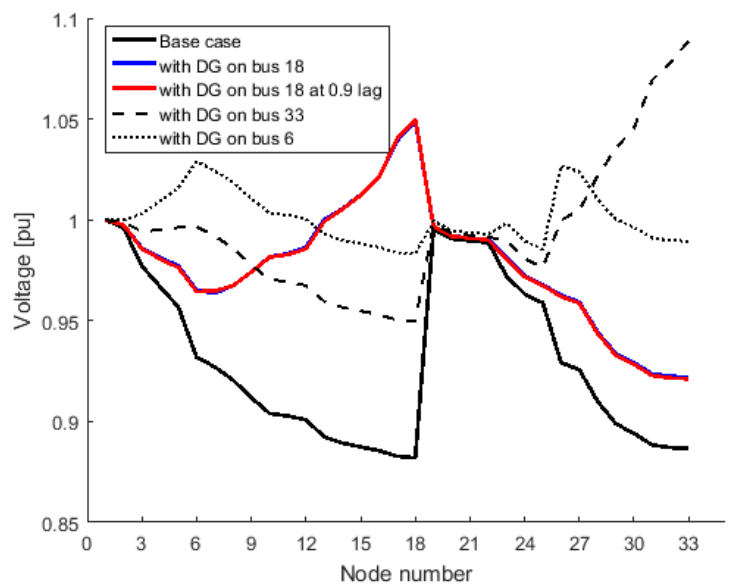

Fig. 22 Voltage profiles of the 33-bus radial distribution system

network Fig. 23. Thus, the node 65 is chosen as the optimal location of the DG. Two other buses are also selected, bus 27 that has the highest Voltage Deviation Index in the second longest branch of the network and bus 8 for its strategic node in the network.

All simulation results using the Voltage Deviation Index and various algorithms for the two test systems are presented in Tables 6 and 7 .

\subsubsection{Results for 33-bus test system using Voltage Deviation Index}

The total active and reactive power losses of the base case are $281.5877 \mathrm{~kW}$ and $187.9595 \mathrm{kVAr}$ respectively. VDI for the same is obtained as 0.11798 at node 18 (i. e. voltage equal to $0.882 \mathrm{pu}$ ).

Fig. 21 shows the grid Voltage Deviation Index when the optimal DG unit for each case has been connected to buses 18, 33 and 6 each time, while Fig. 22 shows

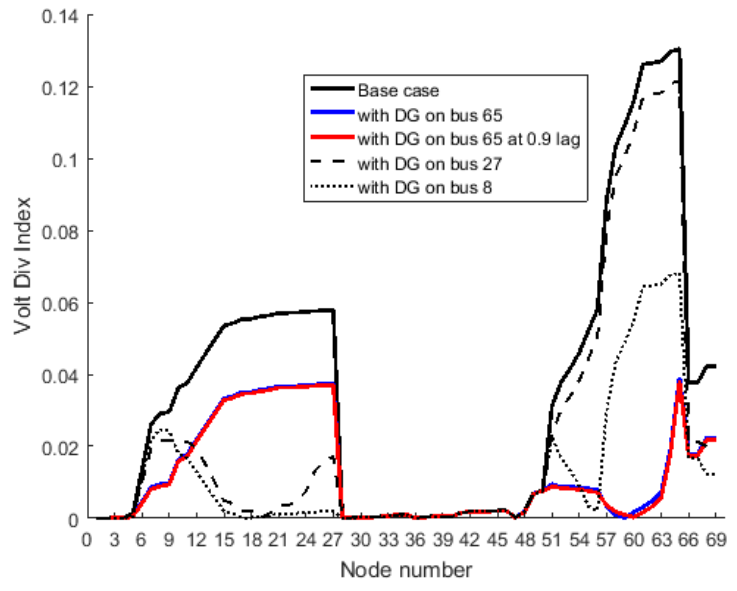

Fig. 23 The 69-bus system Voltage Deviation Index

Table 6 Simulation results of 33-bus system

\begin{tabular}{|c|c|c|c|c|c|}
\hline Methods & $\begin{array}{c}\text { DG } \\
\text { location }\end{array}$ & $\begin{array}{c}\text { DG optimal } \\
\text { size }(\mathrm{MW})\end{array}$ & $\begin{array}{c}P_{\text {loss }} \\
(\mathrm{kW}) \\
(\mathrm{TLR} \%)\end{array}$ & $\begin{array}{c}Q_{\text {loss }} \\
(\mathrm{kVAr}) \\
(\mathrm{TLR} \%)\end{array}$ & $\begin{array}{l}V_{\min } \\
(\mathrm{pu})\end{array}$ \\
\hline $\begin{array}{l}\text { Base } \\
\text { case }\end{array}$ & & & 281.578 & 187.560 & 0.882 \\
\hline \multirow{2}{*}{ GWO } & upf & 1.6407 & $\begin{array}{c}229.224 \\
(18.59)\end{array}$ & $\begin{array}{c}176.974 \\
(5,84)\end{array}$ & 0.922 \\
\hline & lag & 1.4145 & $\begin{array}{c}188.094 \\
(33.20)\end{array}$ & $\begin{array}{l}143.738 \\
(23.52)\end{array}$ & 0.9212 \\
\hline \multirow{2}{*}{ WOA } & upf & 1.6408 & $\begin{array}{c}229.063 \\
(18.65)\end{array}$ & $\begin{array}{c}176.8137 \\
(5.93)\end{array}$ & 0.9212 \\
\hline & lag & 1.4144 & $\begin{array}{c}186.7024 \\
(33.696)\end{array}$ & $\begin{array}{c}142.1917 \\
(24.35)\end{array}$ & 0.9214 \\
\hline \multirow{2}{*}{ PSO } & \multirow{2}{*}{18} & 1.6408 & $\begin{array}{c}229.0521 \\
(18.657)\end{array}$ & $\begin{array}{c}176.8029 \\
(5.93)\end{array}$ & 0.922 \\
\hline & & 1.4144 & $\begin{array}{l}187.633 \\
(33.366)\end{array}$ & $\begin{array}{c}143.2277 \\
(23.798)\end{array}$ & 0.9215 \\
\hline
\end{tabular}

Table 7 Simulation results of 69 -bus system

\begin{tabular}{|c|c|c|c|c|c|}
\hline Methods & $\begin{array}{c}\text { DG } \\
\text { location }\end{array}$ & $\begin{array}{c}\text { DG optimal } \\
\text { size }(\mathrm{MW})\end{array}$ & $\begin{array}{c}P_{\text {loss }} \\
(\mathrm{kW}) \\
(\mathrm{TLR} \%)\end{array}$ & $\begin{array}{c}Q_{\text {loss }} \\
(\mathrm{kVAr}) \\
(\mathrm{TLR} \%)\end{array}$ & $\begin{array}{l}V_{\min } \\
(\mathrm{pu})\end{array}$ \\
\hline $\begin{array}{l}\text { Base } \\
\text { case }\end{array}$ & & & 337.3014 & 150.664 & 0.8697 \\
\hline \multirow{2}{*}{ GWO } & upf & 2.3379 & $\begin{array}{l}186.453 \\
(44.72)\end{array}$ & $\begin{array}{c}90.6358 \\
(39.84)\end{array}$ & 0.9626 \\
\hline & lag & 2.1689 & $\begin{array}{c}116.0727 \\
(65.58)\end{array}$ & $\begin{array}{c}60.7789 \\
(59.66)\end{array}$ & 0.9632 \\
\hline \multirow{2}{*}{ WOA } & upf & 2.3380 & $\begin{array}{l}188.078 \\
(44.24)\end{array}$ & $\begin{array}{l}91.3711 \\
(39.35)\end{array}$ & 0.9628 \\
\hline & lag & 2.1689 & $\begin{array}{c}113.7712 \\
(66.27)\end{array}$ & $\begin{array}{l}59.702 \\
(60.37)\end{array}$ & 0.9629 \\
\hline \multirow{2}{*}{ PSO } & \multirow{2}{*}{65} & 2.3380 & $\begin{array}{c}186.2266 \\
(44.79)\end{array}$ & $\begin{array}{c}90.5329 \\
(39.91)\end{array}$ & 0.9633 \\
\hline & & 2.1689 & $\begin{array}{c}116.7041 \\
(65.40)\end{array}$ & $\begin{array}{c}61.0729 \\
(59.46)\end{array}$ & 0.9626 \\
\hline
\end{tabular}


the profiles grid bus voltage for the same cases. It should be noted that the optimal size of Distributed Generation obtained for a unit power factor is $1.6407 \mathrm{MW}, 3.2891 \mathrm{MW}$ and 4.9766 MW when the Distributed Generation unit is connected to buses 18,33 and 6 , respectively.

With the installation of an optimal size DG operating at the pf unit on bus 18 , the active and reactive power losses obtained are $229.224 \mathrm{~kW}$ and $176.974 \mathrm{kVAr}$, resulting in reductions of $18.59 \%$ and $5.84 \%$ respectively compared to the case without DG installation and, in the case of DG operating with $0.9 \mathrm{pf}$ lag, the active and reactive power losses obtained are $188.094 \mathrm{~kW}$ and $143.738 \mathrm{kVAr}$, or a reduction of $33.20 \%$ and $23.52 \%$ respectively. It should be noted that the optimal size of Distributed Generation obtained for $0.9 \mathrm{pf}$ lag is $1.4145 \mathrm{MW}$.

Figs. 24 and 25 present the network power losses in each branch of the system when DG unit is connected at buses 18,33 , and 6 .

\subsubsection{Results for 69-bus test system using Voltage Deviation Index}

The total active and reactive power losses of the base case, without allocating DG, are $337.277 \mathrm{~kW}$ and $150.653 \mathrm{kVAR}$ respectively. VDI for the same is obtained as 0.1303 at node 65 (i.e. the voltage equal to $0.8696 \mathrm{pu}$ ).

Fig. 23 shows the 69-bus es network Voltage Deviation Index when the optimal DG unit for each case was connected to buses 27, 65 and 8, respectively, while Fig. 26 shows the network bus voltage profiles when the optimal DG unit is connected to the same buses as before. The optimal size of the Distributed Generation obtained for a unit power factor is $0.9794 \mathrm{MW}, 2.3379 \mathrm{MW}$ and 7.2112 MW when the Distributed Generation unit is connected to buses 27,65 and 8 respectively.

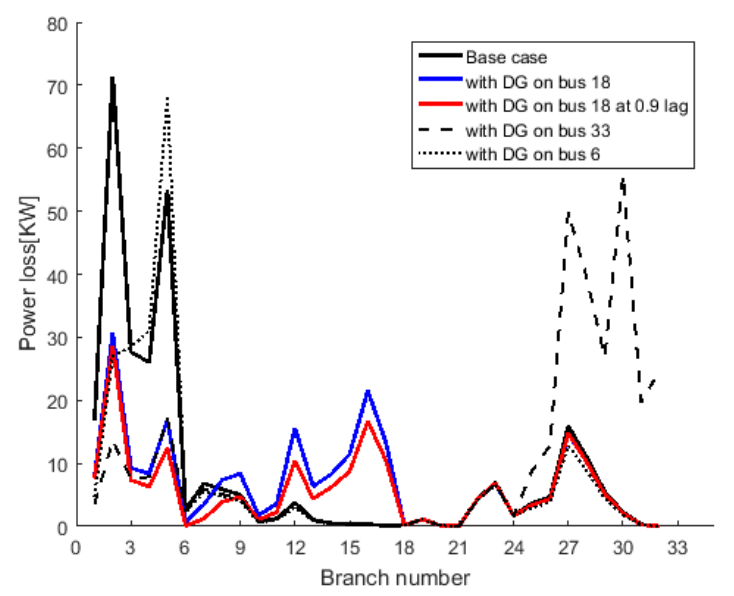

Fig. 24 Active power lines losses of the 33-bus radial distribution system

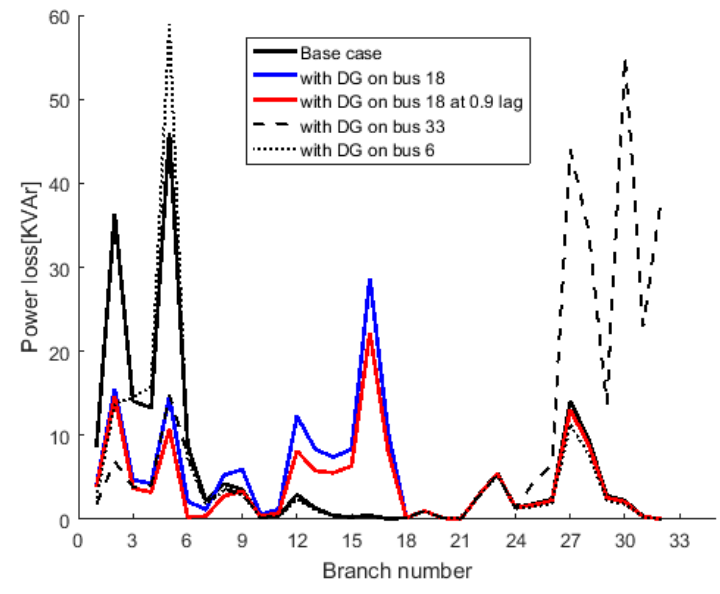

Fig. 25 Reactive power losses of the 33-bus radial distribution system

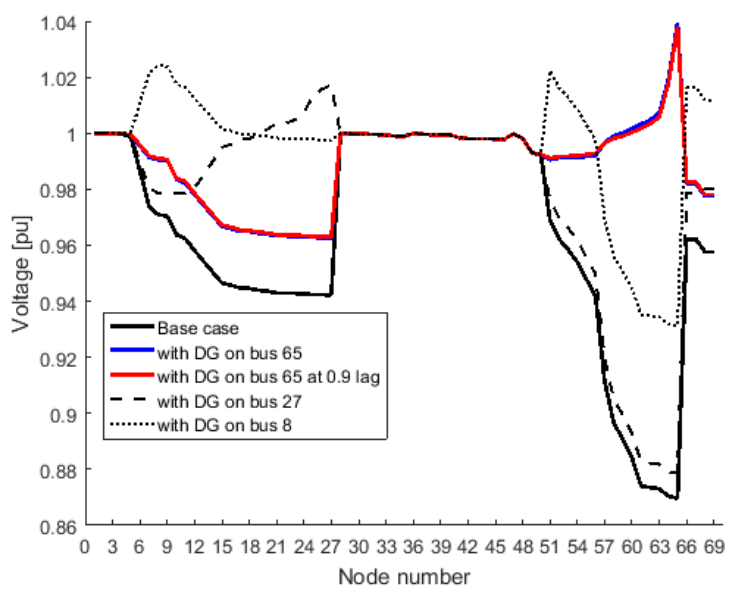

Fig. 26 Voltage profiles of the 69-bus radial distribution system

With the installation of an optimal size DG operating at the power factor unit on bus 65 , the active and the reactive power losses obtained are respectively $186.453 \mathrm{~kW}$ and $90.6358 \mathrm{kVAr}$, resulting in reductions of $44.72 \%$ and $39.84 \%$ respectively compared to the case without DG installation and in the case of Distributed Generation operating with $0.9 \mathrm{pf}$ lag, the active and the reactive power losses obtained are $116.0727 \mathrm{~kW}$ and $60.7789 \mathrm{kVAR}$, representing reductions of $65.58 \%$ and $59.66 \%$ respectively.

Figs. 27 and 28 show the network power losses in each branch of the system when a DG unit with an optimal size and working up is connected to buses 27, 65 and 8 respectively, and also in the case of a DG unit with an optimal size working at $0.9 \mathrm{pf}$ lag is connected to bus 65 .

\section{Comparison of results}

A summary of the results obtained for the 33 and 69-bus test systems with the approaches based on the Index Vector Method, the Voltage Stability Index and the Voltage Deviation Index is presented in Tables 8 and 9. 


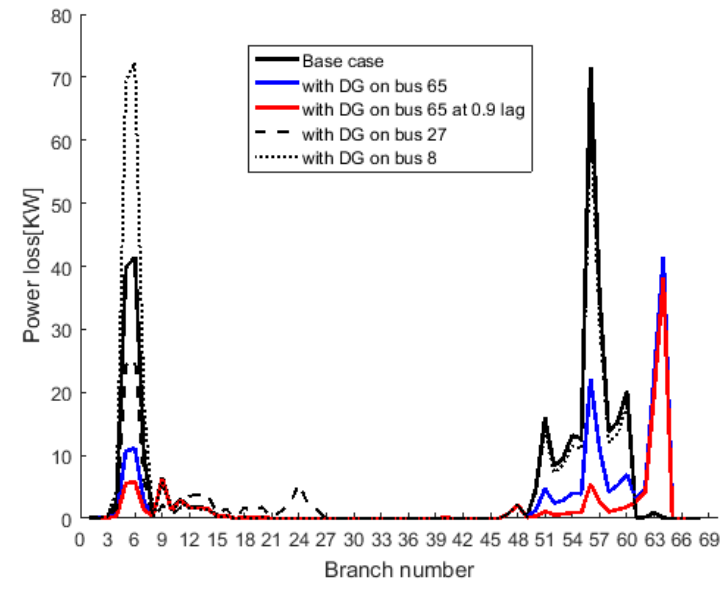

Fig. 27 Active power lines losses of the 69-bus radial distribution system

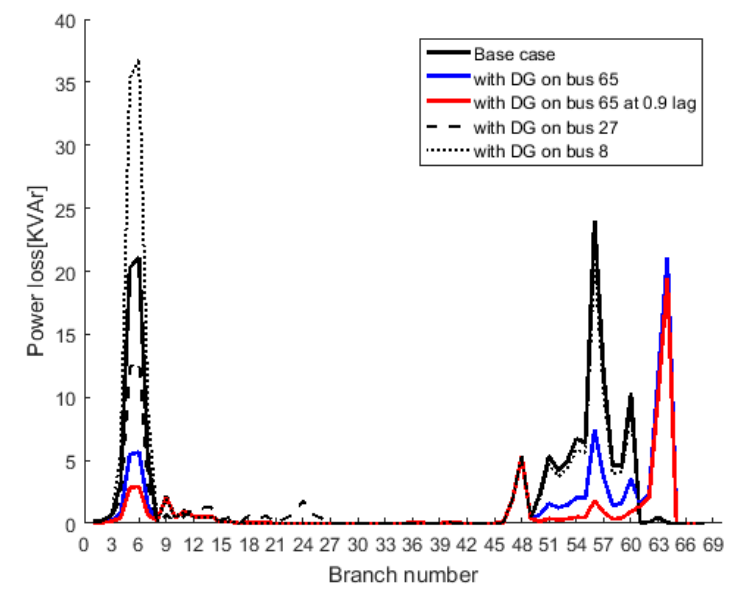

Fig. 28 Reactive power lines losses of the 69-bus radial distribution system
A comparison of the results corresponding to active and reactive power losses, minimum voltage level and DG dimensions was provided for both test systems taking into account the installation of the DG at unit and at 0.9 lagging power factor.

For both test systems, it can be concluded that the installation of an optimal size DG at the optimal location leads to a significant reduction in power losses. In addition, when the decentralized generating unit produces both active and reactive power (at a lag power factor of 0.9), network losses are lower than when only active power is fed into the grid, the voltage is also slightly improved, regardless of the index used.

The best results in terms of power losses reduction and minimum bus voltage are obtained for the VSI index with DG unit operating at 0.9 power factor. But it requires a significant DG size compared to the other two indices.

Noting that the Index Vector Method gives satisfactory results with a DG size lower than that obtained in the case of VSI.

On the other hand, the results obtained show that the three algorithms give very similar values.

\section{Conclusion}

In the present investigation, the DG units impact on radial power network was studied considering losses reduction and voltage profile improvement. Analyses were carried out on the IEEE 33 and 69 bus distribution systems using

Table 8 Simulation results of 33-bus system

\begin{tabular}{|c|c|c|c|c|c|c|c|}
\hline & \multirow[t]{2}{*}{ Without DG } & \multicolumn{3}{|c|}{ With DG at unity pf } & \multicolumn{3}{|c|}{ With DG at $0.9 \mathrm{pf}$ lag } \\
\hline & & IVM & VSI & VDI & IVM & VSI & VDI \\
\hline optimal DG bus location & - & 30 & 6 & 18 & 30 & 6 & 18 \\
\hline DG optimal size (MW) & - & 1.6319 & 3.240 & 1.6407 & 1.7995 & 3.0206 & 1.4146 \\
\hline total power loss (kW) & 281.588 & 151.6819 & 145.151 & 229.2246 & 106.3945 & 96.483 & 188.0949 \\
\hline total reactive power loss (kVAr) & 187.96 & 106.913 & 105.206 & 176.9749 & 77.0343 & 74.251 & 143.7386 \\
\hline$V_{\min }(\mathrm{pu})$ & 0.882 & 0.9184 & 0.9487 & 0.922 & 0.9281 & 0.9562 & 0.9217 \\
\hline
\end{tabular}

Table 9 Simulation results of 69-bus system

\begin{tabular}{|c|c|c|c|c|c|c|c|}
\hline & \multirow[t]{2}{*}{ Without DG } & \multicolumn{3}{|c|}{ With DG at unity pf } & \multicolumn{3}{|c|}{ With DG at $0.9 \mathrm{pf}$ lag } \\
\hline & & IVM & VSI & VDI & IVM & VSI & VDI \\
\hline optimal DG bus location & - & 61 & 61 & 65 & 61 & 61 & 65 \\
\hline DG optimal size (MW) & - & 1.9043 & 2.687 & 2.3379 & 2.0446 & 2.699 & 2.1689 \\
\hline total power loss (kW) & 337.301 & 113.0785 & 139.766 & 186.453 & 51.7467 & 73.508 & 116.0727 \\
\hline total reactive power loss (kVAr) & 150.664 & 54.3294 & 63.613 & 90.6358 & 280549 & 35.428 & 60.7789 \\
\hline$V_{\min }(\mathrm{pu})$ & 0.8697 & 0.9594 & 0.9657 & 0.9626 & 0.9627 & 0.9685 & 0.9632 \\
\hline
\end{tabular}


three methods (Index) for optimally allocating Distributed Generation and three methods to determine their optimal sizes. The study is carried out on DG operating at unity power factor and on DG operating at 0.9 power factor lag. From the simulation results, it is very clear that whatever method is used, the optimal allocation of Distributed Generation in the radial distribution system will greatly reduce the total power loss and improve the system voltage profile. On the other hand, a wrong allocation can lead to an increase in power losses.

Due to its contribution to the system's reactive power supply, DG at lagging power factor yields better results compared to DGs at unity power factor.

\section{References}

[1] Emad, A. M., Al-Attar, A. M., Yasunori, M. "Hybrid GMSA for Optimal Placement and Sizing of Distributed Generation and Shunt Capacitors", Journal of Engineering Science and Technology Review, 11(1), pp. 55-65, 2018. https://doi.org/10.25103/jestr.111.07

[2] Photovoltaics, D. G. "IEEE Std 1547-2003 IEEE Standard for Interconnecting Distributed Resources with Electric Power Systems", IEEE, Piscataway, NJ, USA, 2003. https://doi.org/10.1109/IEEESTD.2003.94285

[3] Murty, V. V. S. N., Kumar, A. "Optimal placement of DG in radial distribution systems based on new voltage stability index under load growth", International Journal of Electrical Power \& Energy Systems, 69, pp. 246-256, 2015. https://doi.org/10.1016/j.ijepes.2014.12.080

[4] Hung, D. Q., Mithulananthan, N. "Multiple Distributed Generator Placement in Primary Distribution Networks for Loss Reduction", IEEE Transactions on Industrial Electronics, 60(4), pp. 1700-1708, 2013. https://doi.org/10.1109/TIE.2011.2112316

[5] Viral, R., Khatod, D. K. "An analytical approach for sizing and siting of DGs in balanced radial distribution networks for loss minimization", International Journal of Electrical Power \& Energy Systems, 67, pp. 191-201, 2015. https://doi.org/10.1016/j.ijepes.2014.11.017

[6] Mirjalili, S., Mirjalili, S. M., Lewis, A. "Grey Wolf Optimizer", Advances in Engineering Software, 69, pp. 46-61, 2014. https://doi.org/10.1016/j.advengsoft.2013.12.007

[7] Mirjalili, S., Lewis, A. "The Whale Optimization Algorithm", Advances in Engineering Software, 95, pp. 51-67, 2016. https://doi.org/10.1016/j.advengsoft.2016.01.008

[8] M'hamdi, B., Teguar, M., Mekhaldi, A. "Optimal Design of Corona Ring on HV Composite Insulator Using PSO Approach with Dynamic Population Size", IEEE Transactions on Dielectrics and Electrical Insulation, 23(2), pp. 1048-1057, 2016. https://doi.org/10.1109/TDEI.2015.005383
The best result in terms of losses reduction and minimum bus voltage is obtained for the VSI index with a DG unit at a power factor of 0.9 compared to the other indixes. But it requires a DG with large size compared to the other two indixes.

In this paper, the optimal DG size problem is solved with three metaheuristic algorithms, the results obtained show that the three algorithms give very similar values.

[9] Murthy, V. V. S. N., Kumar, A. "Comparison of optimal DG allocation methods in radial distribution systems based on sensitivity approaches", International Journal of Electrical Power \& Energy Systems, 53, pp. 450-467, 2013. https://doi.org/10.1016/j.ijepes.2013.05.018

[10] Hadidian-Moghaddam, M. J., Arabi-Nowdeh, S., Bigdeli, M., Azizian, D. "A multi-objective optimal sizing and siting of distributed generation using ant lion optimization technique", Ain Shams Engineering Journal, 9(4), pp. 2101-2109, 2018. https://doi.org/10.1016/j.asej.2017.03.001

[11] Abaci, K., Yamacli, V. "Differential search algorithm for solving multi-objective optimal power flow problem", International Journal of Electrical Power \& Energy Systems, 79, pp. 1-10, 2016. https://doi.org/10.1016/j.ijepes.2015.12.021

[12] Vita, V. "Development of a Decision-Making Algorithm for the Optimum Size and Placement of Distributed Generation Units in Distribution Networks", Energies, 10(9), Article number: 1433, 2017. https://doi.org/10.3390/en10091433

[13] Essallah, S., Bouallegue, A., Khedher, A. "Optimal Sizing and Placement of DG Units in Radial Distribution System", International Journal of Renewable Energy Research, 8(1), pp. 166-177, 2018. [online] Available at: https://www.ijrer.org/ijrer/index.php/ijrer/ article/view/6666 [Accessed: 17 April 2019]

[14] Karimyan, P., Vahidi, B., Abedi, M., Ahadi, S. M. "Optimal dispatchable DG allocation in a distribution network considering load growth with a mixed-PSO algorithm", Turkish Journal of Electrical Engineering \& Computer Sciences, 24, pp. 3049-3065, 2016. https://doi.org/10.3906/elk-1404-207 